\title{
Adversities In Mandarin of College of Education Students of Bulacan State University
}

\author{
Jovita E. Villanueva ${ }^{1}$ \\ ${ }^{1}$ College of Education Bulacan State University, City of Malolos Bulacan, Philippines, 3000
}

\begin{abstract}
Background/Objectives: The paper looked into the various adversities the students of Bulacan State University in studying Mandarin as a foreign language. Methods/Statistical analysis: Mandarin language has been included in the curriculum of education course of Bulacan State University. The various areas considered were reading, speaking, listening, writing, learning materials, medium of instruction and teaching methodology. Findings: The research instrument used was created by the researcher considering the four basic skills in communications and other areas in studying Mandarin where the researcher believed students are having adversities. The study revealed that students of Bulacan State University are having problem in various aspects of the study of Mandarin as foreign language more particularly on vocabulary enrichment. Improvements/Applications: The researcher developed an instructional material in Mandarin that will help enrich the vocabulary of the students thereby enhancing the students competency in the mandarin language.
\end{abstract}

\section{Index Terms}

Adversities, Mandarin, Foreign language, Communication

\footnotetext{
Corresponding author : Jovita E. Villanueva

jovita.villanueva@bulsu.edu.ph

- Manuscript received July 20, 2017.

- Revised August 7, 2017; Accepted September 1, 2017.

- Date of publication September 30, 2017.

(C) The Academic Society of Convergence Science Inc.

2546-1583 $\odot 2017$ IJEMR. Personal use is permitted, but republication/redistribution requires IJEMR permission.
} 


\section{INTRODUCTION}

Each and every institution adheres to the vision of producing globally competitive graduates. Being globally competitive today means being able to meet the demands if the international market. One of those demands is being to coexist with professionals from other countries and to coexist means being able to communicate. Communication is very important in our everyday lives. To understand others and to be able to coexist with them there is a need to communicate. In order to communicate we use different means of communication like the verbal and non-verbal communications. In verbal communication there is the spoken and written language.

Learning a language at a very young age includes learning the basics of reading and writing. In the English language, it starts from learning the alphabet. With the borderless society that we have today, there is a need to learn other language in order to reach every person, every culture. Having knowledge of foreign language is an edge specially if someone would like to travel or work abroad. Is someone can speak a language other than his native language specially if the language is the one which is being spoken in the country where someone works, it will be an advantage for him.

In the Philippines foreign language has been taught in big colleges and universities to those students taking courses that are in line with business and foreign service.

Most common foreign languages being offered in the Philippines are Spanish, French and Japanese. Recent addition to the list of foreign languages being offered is the Mandarin language.

According to Chabal (2014) [1] with the opening of China to the outside world more and more people are learning Mandarin. People primarily use this learning for business and pleasure trips.

The English word "mandarin" (from Portuguese mandarim, from Malay menteri, from Sanskrit mantrin, meaning "minister or counsellor") originally meant an official of the Ming and Qing empires[2] Since their native varieties were often mutually unintelligible, these officials communicated using a koiné based on various northern varieties. When Jesuit missionaries learned this standard language in the 16th century, they called it "Mandarin", from its Chinese name Guānhuà, or "language of the officials"[3].

In everyday English, "Mandarin" refers to Standard Chinese, which is often called simply "Chinese". Standard Chinese is based on the particular Mandarin dialect spoken in Beijing, with some lexical and syntactic influence from other Mandarin dialects. It is the official spoken language of the People's Republic of China (PRC), the official language of the Republic of China (ROC/Taiwan), and one of the four official languages of the Republic of Singapore. It also functions as the language of instruction in the PRC and in Taiwan. It is one of the six official languages of the United Nations, under the name "Chinese". Chinese speakers refer to the modern standard language as (1) Pǔtōnghua literally "common speech") in China, (2) Guóyǔ, literally "national language") in Taiwan, or Huáyu in Malaysia, Singapore and Philippines, but not as Guānhuà. This article uses the term "Mandarin" in the sense used by linguists, referring to the diverse group of dialects spoken in northern and southwestern China, which Chinese linguists call Guānhuà. The alternative term Běifänghuà, or "Northern dialect(s)", is used less and less among Chinese linguists. By extension, the term "Old Mandarin" is used by linguists to refer to the northern dialects recorded in materials from the Yuan dynasty.

Eaton (2014) [4] Mandarin Chinese is spoken by around 800 million people worldwide. That's twice the number of English speakers.

With China becoming increasingly powerful in business, there's a growing need for Mandarin speakers.

\section{RESEARCH MODEL}

The general problem of the study was: What were the adversities of Bulacan State University students taking Mandarin as Foreign Language?

Specifically, the study sought to answer the following questions:

1. How may the profile of students of Bulacan State University taking Mandarin as foreign language be described in terms of:

$$
\begin{aligned}
& 1.1 \text { age } \\
& 1.2 \text { sex }
\end{aligned}
$$

2. What are the adversities of Bulacan State University Students in learning Mandarin?
2.1 reading
2.2 speaking
2.3 listening
2.4 writing
2.5 learning materials
2.6 medium of instruction
2.7 teaching methodology?

3. Based on the result of the study, what intervention program may be developed to address the students adversities in studying mandarin? 


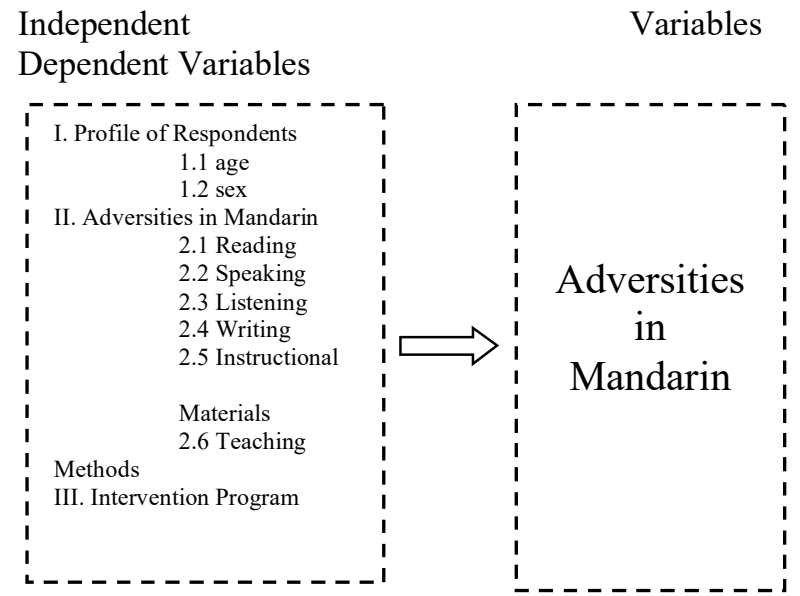

Fig. 1. Conceptual Framework

Fig. 1 showed the conceptual framework of the study. This research was conducted to find out the different problems that students of Bulacan State University in studying Mandarin as foreign language. Respondents of this study were students of college of education taking mandarin. The study was conducted in the first semester of 2015-2016.

\section{A. Method of the Study}

This study used the descriptive- survey method of research. It is the most common way of gathering data and information through the use of questionnaires, unstructured interviews or scheduled interview, and observation. The descriptive survey research questionnaire was the main tool used in data gathering for this study. The questionnaire contained questions about their adversities in the various identified variables like reading, speaking, listening, writing, learning materials and teaching methodology. The student respondents were asked to identify their adversities in various areas of the study of mandarin.

Data gathered were tallied, tabulated using frequency and ranking for the various adversities in Mandarin and frequency percentage were used for the profile of the respondents with the aid of Statistical Package for Social Sciences (SPSS) version 20 .

\section{RESEARCH RESULTS}

Table 1. FrequenCy Distribution As to AGE

\begin{tabular}{ccc}
\hline \hline Age & Frequency & Percentage \\
\hline 15 & 11 & 11.2 \\
16 & 5 & 5.1 \\
17 & 54 & 55.1 \\
18 & 21 & 21.4 \\
19 & 3 & 3.1 \\
20 & 2 & 2.0 \\
21 & 2 & 2.0 \\
Total & 97 & 100.0 \\
\hline \hline
\end{tabular}

Table 1 showed the frequency distribution of the age where majority of the students were aged 17 with the frequency of 54 or about $55.1 \%$ followed by 18 years old with a frequency of 21 or $21.4 \%$, followed by age 11 or $11.2 \%$, then age 16 with 5 as frequency with a percentage of 5.1and ages 20-21 with both frequency of 2 or 2.0 percent.

\begin{tabular}{ccc}
\hline \multicolumn{3}{l}{ Table 2. FREQUENCY DISTRIBUTION AS TO SEX } \\
\hline Sex & Frequency & Percentage \\
\hline Male & 29 & 29.89 \\
Female & 68 & 70.11 \\
Total & 97 & 100.0 \\
\hline
\end{tabular}

Showcased in Table 2 was the frequency pertaining to respondents' sex, majority of the student respondents were female as indicated by a frequency of 68 or 70.11 percent while the male were 29 or about $29.89 \%$. Such finding supports the idea that teacher education is female dominated course.

Table 3. FREQUENCY DISTRIBUTION AND RANKING AS TO LISTENING SKILLS

\begin{tabular}{lcc}
\hline \multicolumn{1}{c}{ Listening Skills } & Frequency & Rank \\
\hline $\begin{array}{l}\text { 1. Retain chunks of language in short- } \\
\text { term memory. }\end{array}$ & 67 & 1 \\
$\begin{array}{l}\text { 2. Discriminate among the distinctive } \\
\text { sounds in the new language }\end{array}$ & 42 & 9 \\
$\begin{array}{l}\text { 3. Recognize stress and rhythm } \\
\text { patterns, tone patterns, intonational } \\
\text { contours. }\end{array}$ & 58 & 2 \\
$\begin{array}{l}\text { 4. Capable of recognizing reduced } \\
\text { forms of words. }\end{array}$ & 24 & 10 \\
$\begin{array}{l}\text { 5. Distinguish word boundaries. } \\
\text { 6. Recognizes typical word-order } \\
\text { patterns. }\end{array}$ & 44 & 7 \\
$\begin{array}{l}\text { 7. Recognizes vocabulary. } \\
\text { 8. Detects key words, such as those }\end{array}$ & 46 & 4 \\
identifying topics and ideas. \\
$\begin{array}{l}\text { 9. Guesses meaning from context. } \\
\begin{array}{l}\text { 10. Recognizes grammatical word } \\
\text { classes. }\end{array}\end{array}$ & 45 & 5.5 \\
\hline \hline
\end{tabular}

Revealed in Table 3, is the frequency distribution and ranking for listening skills, which indicated that among the adversities of students in Mandarin the ability to retain chunk of language in short term memory is the number one problem with a frequency of 67 , followed by the adversity in recognizing stress and rhythm pattern, tone patterns, intonational contours was ranked number 2 as posted in the frequency of 58. The problem in recognizing grammatical word classes was ranked number 3 by having a frequency of 52, then the adversity in recognizing typical word-order pattern was number 4 as displayed in the frequency of 46, tied at rank 5.5 were adversities pertaining to recognizing vocabulary and guesses meaning from context both had frequency of 45 , the adversity on distinguishing word boundary at rank number 7 as revealed in the 
frequency of 44 , then problem on detecting key words, such as those identifying topics and ideas ranked number 8 with a frequency of 4 . Meanwhile ranked number 9 was problem on discriminating among the distinctive sounds in the new language with frequency of 42 and ranked number 10 was the problem on the capacity to recognize reduced forms of words as indicated by the frequency of 24 .

Table 4. FREQUENCY DISTRIBUTION AND RANKING AS TO SPEAKING SKILLS

\begin{tabular}{|c|c|c|}
\hline Speaking Skills & Frequency & Rank \\
\hline $\begin{array}{l}\text { 11. Detects sentence constituents, such } \\
\text { as subject, verb, object, prepositions, } \\
\text { and the likes, pronounce the distinctive } \\
\text { sounds of a language clearly enough so } \\
\text { that people can distinguish them. This } \\
\text { includes making tonal distinctions. }\end{array}$ & 53 & 3 \\
\hline $\begin{array}{l}\text { 12. Uses stress and rhythmic patterns, } \\
\text { and intonation patterns of the language } \\
\text { clearly enough so that people can } \\
\text { understand what is said. }\end{array}$ & 53 & 3 \\
\hline $\begin{array}{l}\text { 13. Uses the correct forms of words. } \\
\text { This may mean, for example, changes } \\
\text { in the tense, case, or gender. }\end{array}$ & 46 & 6.5 \\
\hline $\begin{array}{l}\text { 14. Capable of putting words together } \\
\text { in correct word order. }\end{array}$ & 53 & 3 \\
\hline 15. Uses vocabulary appropriately. & 57 & 1 \\
\hline $\begin{array}{l}\text { 16. Uses the register or language } \\
\text { variety that is appropriate to the } \\
\text { situation and the relationship to the } \\
\text { conversation partner. }\end{array}$ & 52 & 5 \\
\hline $\begin{array}{l}\text { 17. Makes clear to the listener the } \\
\text { main sentence constituents, such as } \\
\text { subject, verb, object, by whatever } \\
\text { means the language uses. }\end{array}$ & 42 & 8 \\
\hline $\begin{array}{l}\text { 18. Makes the main ideas stand out } \\
\text { from supporting ideas or information. }\end{array}$ & 46 & 6.5 \\
\hline
\end{tabular}

Table 4 shows the frequency and ranking for speaking skills, the major problem in speaking skills was the used of vocabulary appropriately since it posted a frequency of 57, followed by the problem on detecting sentence constituents, such as subject, verb, object, prepositions, and the likes, pronounce the distinctive sounds of a language clearly enough so that people can distinguish them. This includes making tonal distinctions, problem on capability of putting words together in correct word order and uses stress and rhythmic patterns, and intonation patterns of the language clearly enough so that people can understand what is said all ranked number 3 since they all have frequency of 53 each. Ranked number 5 with frequency of 52 was problem on using the register or language variety that is appropriate to the situation and the relationship to the conversation partner, followed by the problem on using the correct forms of words. This may mean, for example, changes in the tense, case, or gender and makes the main ideas stand out from supporting ideas or information both register a frequency of 46 that made it ranked number 6.5. The least problem making clear to the listener the main sentence constituents, such as subject, verb, object, by whatever means the language uses is ranked number 8 with a frequency of 42 .

Meanwhile, Table 5 shows the frequency and ranking for the adversities in reading skills. The number 1 problem in reading skills Detects sentence constituents, such as subject, verb, object, prepositions, etc.. Ranked 2 Makes the discourse hang together so that people can follow what you are saying. Ranked number 4 Gets the main point or the most important information, recognizes vocabulary and recognize basic syntactic patterns all has frequency of 43, followed by adversity in recognizing grammatical word classes: noun, adjective, etc. which is ranked 6 with 42 frequency, then ranked 7 figures out the meaning of the words, including unfamiliar vocabulary, from the (written) context with frequency of 38 ,adversity in deciphers the script in an alphabetic system or a syllabary, this means establishing a relationship between sounds and symbols. In a pictograph system, it means associating the meaning of the words with written symbols was ranked 8.5 as indicated by 37 frequency, problem on reconstructing and inferring situations, goals and participants was ranked 8.5 with 37 frequency, problem on using both knowledge of the world and lexical and grammatical cohesive devices to make the foregoing inferences, predict outcomes, and infer links and connections among the parts of the text was ranked 10.5 together with distinguish the main idea from supporting details . Picks out key words, such as those identifying topics and main ideas were ranked 12 having a frequency of 33 and finally the ranked 13 was adjusting reading strategies to different reading purposes, such as skimming for main ideas or studying in-depth by having a frequency of 26 .

Table 5. FREQUENCY AND DISTRIBUTION AS TO READING SKILLS

\begin{tabular}{lcc}
\hline \hline Reading Skills & Frequency & Rank \\
\hline $\begin{array}{l}\text { 19. Deciphers the script. In an } \\
\text { alphabetic system or a syllabary, this } \\
\text { means establishing a relationship } \\
\text { between sounds and symbols. In a } \\
\text { pictograph system, it means associating } \\
\text { the meaning of the words with written } \\
\text { symbols. }\end{array}$ & 37 & 8.5 \\
$\begin{array}{l}\text { 20. Recognizes vocabulary. } \\
\text { 21. Picks out key words, such as those }\end{array}$ & 33 & \\
$\begin{array}{l}\text { identifying topics and main ideas. } \\
\text { 22. Figures out the meaning of the }\end{array}$ & 38 & 72 \\
$\begin{array}{l}\text { words, including unfamiliar vocabulary, } \\
\text { from the (written) context. }\end{array}$ & & \\
$\begin{array}{l}\text { 23. Recognizes grammatical word } \\
\text { classes: noun, adjective, etc. }\end{array}$ & 42 & 6 \\
$\begin{array}{l}\text { 24. Detects sentence constituents, such } \\
\text { as subject, verb, object, prepositions, } \\
\text { etc. }\end{array}$ & 46 & 1
\end{tabular}


25. Recognize basic syntactic patterns.

26. Reconstruct and infer situations, goals and participants.

27. Uses both knowledge of the world and lexical and grammatical cohesive devices to make the foregoing inferences, predict outcomes, and infer links and connections among the parts of the text.

28. Gets the main point or the most important information.

29. Distinguish the main idea from supporting details.

30. Adjust reading strategies to

different reading purposes, such as

skimming for main ideas or studying indepth.

31. Makes the discourse hang together so that people can follow what you are saying.

Table 6. FREQUENCY DISTRIBUTION AND RANKING AS TO WRITING SKILLS

\begin{tabular}{|c|c|c|}
\hline Writing Skills & Frequency & Rank \\
\hline $\begin{array}{l}\text { 32. Uses the orthography correctly, } \\
\text { including the script, and spelling } \\
\text { and punctuation conventions. }\end{array}$ & 42 & 5.5 \\
\hline $\begin{array}{l}\text { 33. Uses the correct forms of } \\
\text { words. This may mean using forms } \\
\text { that express the right tense, or case } \\
\text { or gender. }\end{array}$ & 49 & 2 \\
\hline $\begin{array}{l}\text { 34. Puts words together in correct } \\
\text { word order. }\end{array}$ & 46 & 3 \\
\hline 35. Uses vocabulary correctly. & 55 & 1 \\
\hline $\begin{array}{l}\text { 36. Uses the style appropriate to } \\
\text { the genre and audience. }\end{array}$ & 45 & 4 \\
\hline $\begin{array}{l}\text { 37. Makes the main sentence } \\
\text { constituents, such as subject, verb, } \\
\text { and object, clear to the reader. }\end{array}$ & 38 & 10 \\
\hline $\begin{array}{l}\text { 38. Makes the main ideas distinct } \\
\text { from supporting ideas or } \\
\text { information. }\end{array}$ & 34 & 12 \\
\hline $\begin{array}{l}\text { 39. Makes the text coherent, so that } \\
\text { other people can follow the } \\
\text { development of the ideas. }\end{array}$ & 40 & 8 \\
\hline $\begin{array}{l}\text { 40. Judges how much background } \\
\text { knowledge the audience has on the } \\
\text { subject and make clear what it is } \\
\text { assumed they don't know. }\end{array}$ & 38 & 10 \\
\hline $\begin{array}{l}\text { 41. Uses the orthography correctly, } \\
\text { including the script, and spelling } \\
\text { and punctuation conventions. }\end{array}$ & 38 & 10 \\
\hline 42. Uses vocabulary correctly. & 42 & 5.5 \\
\hline $\begin{array}{l}\text { 43. Uses the style appropriate to the } \\
\text { genre and audience. }\end{array}$ & 41 & 7 \\
\hline $\begin{array}{l}\text { 44. Makes the main sentence } \\
\text { constituents, such as subject, verb, } \\
\text { and object, clear to the reader. }\end{array}$ & 28 & 13 \\
\hline
\end{tabular}

Reflected in Table 6 was the frequency and ranking of the adversities of students pertaining to writing skills. The number 1 problem in writing skills was using vocabulary correctly with a frequency of 55 , followed by the problem on using the correct forms of words. This may mean using forms that express the right tense, or case or gender with a frequency of 49 , ranked 3 was the problem on putting words together in correct word order with 46 frequency, ranked number 4 was problem on using style appropriate for the genre and audience as reflected by the frequency of 45 , ranked 5.5 were uses vocabulary correctly and uses the orthography correctly, including the script, and spelling and punctuation conventions both with frequency of 42 , ranked 7 is uses the style appropriate to the genre and audience with a frequency of 41 , then ranked number 8 makes the text coherent, so that other people can follow the development of the ideas got a frequency of 40, ranked 10 were uses the orthography correctly, including the script, and spelling and punctuation conventions judges how much background knowledge the audience has on the subject and make clear what it is assumed they don't know and makes the main sentence constituents, such as subject, verb, and object, clear to the reader all had a frequency of 38, ranked 13 .

Table 7. FREQUENCY DISTRIBUTION AND RANKING AS TO LEARNING MATERIALS

\begin{tabular}{lcc}
\hline \multicolumn{1}{c}{ Learning Materials } & Frequency & Rank \\
\hline $\begin{array}{l}\text { 45. Books and other publications } \\
\text { are not available in the library }\end{array}$ & 38 & 1.5 \\
$\begin{array}{l}\text { 46. Interactive online materials } \\
\text { are readily available. }\end{array}$ & 30 & 4 \\
$\begin{array}{l}\text { 47. Books were written in both } \\
\text { English and Mandarin for better }\end{array}$ & 38 & 1.5 \\
understanding. & & \\
$\begin{array}{l}\text { 48. DVD videos pertaining to } \\
\text { Chinese language and culture are }\end{array}$ & 33 & 3 \\
$\begin{array}{l}\text { available for the use of the } \\
\text { students. }\end{array}$ & & \\
$\begin{array}{l}\text { 49. Materials for practice } \\
\text { activities like writing are }\end{array}$ & 24 & 6 \\
available. & & \\
50. Chinese books have English \\
or Filipino translation.
\end{tabular}

Meanwhile Table 7 reveals the frequency and ranking for the adversities in learning materials. The number 1 problem in this aspect were Books and other publications are not available in the library and books were written in both English and Mandarin for better understanding both got a frequency of 38, next to it was DVD videos pertaining to Chinese language and culture are available for the use of the students with frequency of 33 , then the adversity on materials for practice activities like writing are available having a frequency of 24 and finally the problem on Chinese books have English or Filipino translation having a frequency of 25 . 
Table 8. Frequency Distribution AND RanKing as MEdiUm OF INSTRUCTION

\begin{tabular}{|c|c|c|}
\hline Medium of Instruction & Frequency & Rank \\
\hline $\begin{array}{l}\text { 51. Learning Chinese is } \\
\text { more interesting if the } \\
\text { medium of instruction is } \\
\text { English or Filipino. }\end{array}$ & 35 & 2 \\
\hline $\begin{array}{l}\text { 52. Asks questions for } \\
\text { clarification since the } \\
\text { medium of instruction is } \\
\text { English or Filipino. }\end{array}$ & 34 & 3 \\
\hline $\begin{array}{l}\text { 53. Easily understands the } \\
\text { context because my } \\
\text { Mandarin Teacher uses } \\
\text { English in discussion. }\end{array}$ & 42 & 1 \\
\hline
\end{tabular}

The problems of students in the medium of instruction were indicated in table 8 , that the students cannot easily understand the context because the Mandarin teacher uses English in discussion as indicated in the frequency of 42 , then problem pertaining to learning Chinese is more interesting if the medium of instruction is in English or Filipino as shown in the frequency of 35 and the last was the problem on asking questions for clarification since the medium of instruction is English or Filipino having a frequency of 34 .

Table 9. FREQUENCY DISTRIBUTION AND RANKING AS TEACHING METHODOLOGIES

\begin{tabular}{lcc}
\hline \hline \multicolumn{1}{c}{ Teaching Methodologies } & Frequency & Rank \\
\hline 56. I prefer lecture type discussion. & 39 & 1 \\
$\begin{array}{l}\text { 57. Our teacher also provides audio } \\
\text { materials for better understanding } \\
\text { of the pronunciation. }\end{array}$ & 37 & 2 \\
$\begin{array}{l}\text { 58. Easily identifies the proper } \\
\text { intonation by listening to audio } \\
\text { materials like DVD and others. }\end{array}$ & 36 & 3 \\
$\begin{array}{l}\text { 59. I understand context better } \\
\text { through watching video clips. } \\
\text { 60. Teacher uses posters and flip } \\
\text { charts in discussion. }\end{array}$ & 34 & 4 \\
\hline \hline
\end{tabular}

Reflected in Table 9 is the frequency and ranking for adversities in Teaching Methodologies. In this aspect, the major problem was their preference to have lecture type discussion since it got a frequency of 39, then followed by the statement our teacher also provides audio materials for better understanding of the of the pronunciation by the frequency of 37 , next problem is on easily identifies the proper intonation by listening to audio materials like DVD and others with a frequency of 36 , next problem is I understand context better through watching video clips by having a frequency of 34 and finally the problem on teachers uses posters and flip charts in discussion.

\section{CONClusion}

Based on the findings, the following conclusions were drawn: (1.)The students are having problem in retain chunks of language in short-term memory; (2.) The students are having problem in using vocabulary appropriately; (3) Mandarin learners cannot detect sentence constituents, such as subject, verb, object, prepositions, etc; (4) Students cannot use vocabulary correctly; (5.)There are no books and other publications that are available in the libraries; (6.) Most books were not written in both English and Mandarin for better understanding; (7) Students have problem on easily understanding the context of the sentence of the Mandarin teacher because he does not use English in discussion and (8.) Students taking Mandarin prefer lecture type discussion.

On the bases of the conclusion, the following are the recommendations (1.) Teaching materials in Mandarin should have translation in English; (2.) Provide enough textbooks that should be made available to the students; (3.) Training of faculty members teaching mandarin should be continuous to meet the adversities of the students; (4.) Teachers handling Mandarin should be able to speak language which is common to their students; (5.) Students should be given enough activities that will help enrich their vocabulary and (6) Teachers should use teaching methodologies that will help the students improve their speaking, reading, listening and writing skills.

\section{REFERENCES}

[1] Marian, V., Chabal, S., Bartolotti, J., Bradley, K., \& Hernandez, A. E. (2014). Differential recruitment of executive control regions during phonological competition in monolinguals and bilinguals. Brain and language, 139, 108117. Retrieved from http://www.academia.edu/9407531/ Differential_recruitment_of_executive_control_regions_duri ng_phonological_competition_in_monolinguals_and_biilingu als.

[2] Chomsky, N. (1975). The logical structure of linguistic theory (p. 573). New York: Plenum press.

[3] Guven, C. Islam, A. (2015). Age at migration, language proficiency, and socioeconomic outcomes: evidence from Australia. Demography, 52(2), 513-542.

[4] Eaton, A. 2014 title Retrieved from http://www.Leicester mercury.co.uk 